\title{
Article \\ The Organization of Animal Protection Investigations and the Animal Harm Spectrum: Canadian Data, International Lessons
}

\author{
Kendra Coulter
}

Citation: Coulter, Kendra. 2022. The Organization of Animal Protection Investigations and the Animal Harm Spectrum: Canadian Data,

International Lessons. Social Sciences 11: 22. https://doi.org/10.3390/ socsci11010022

Academic Editors: Kimberly Spanjol, Cathryn Lavery and Heath Grant

Received: 9 September 2021

Accepted: 16 December 2021

Published: 13 January 2022

Publisher's Note: MDPI stays neutral with regard to jurisdictional claims in published maps and institutional affiliations.

Copyright: (C) 2022 by the author. Licensee MDPI, Basel, Switzerland. This article is an open access article distributed under the terms and conditions of the Creative Commons Attribution (CC BY) license (https:// creativecommons.org/licenses/by/ $4.0 /)$.
Department of Labour Studies, Brock University, St. Catharines, ON L2S 3A1, Canada; kcoulter@brocku.ca

\begin{abstract}
This paper offers the first overview of the Canadian animal cruelty investigations landscape. First, the public and private sector organizations responsible for enforcement are explained, followed by examination of the implications of this patchwork for reporting suspected cruelty. Key statistical data are presented about the types of issues and cases and investigator responses. Initial recommendations are then proposed, and the value of the animal harm spectrum is discussed, including how it can be mobilized to strengthen the operations of animal protection work and animal welfare policy across nations.
\end{abstract}

Keywords: animal protection; animal organizations; human-animal violence link; animals and public policy; green criminology; humane criminology; humane jobs; humane law enforcement; animal harm

\section{Introduction}

Given the breadth of other animal species and individual animals, animal protection is a large umbrella under which there are a broad range of political, legal, economic, and investigative strategies. Animal protection work can focus on confronting illegal cruelty and/or on practices that harm animals, but which are currently legal and often undertaken by corporate actors. Both of these spheres of protection work are important. This paper concentrates on the former: responses to illegal cruelty.

Across industrialized countries of the anglo-global north, responsibility for the frontline investigations and enforcement of animal cruelty legislation is commonly assigned to nonprofit animal welfare charities-particularly national Societies for the Prevention of Cruelty to Animals (SPCAs). This is the case in England, Wales, Scotland, Ireland, Australia, and New Zealand (Coulter and Fitzgerald 2019; Rodriguez Ferrere et al. 2019; Hughes and Lawson 2011; Morton et al. 2021). The United States, where the majority of this work is undertaken by and split about evenly between policing agencies or public animal care and control services (each is responsible for $46-47 \%$ of regions, while nonprofits cover the remaining areas), is the exception (National Link Coalition 2021). The multi-national pattern of assigning or off-loading work to charities is atypical for law enforcement which is normally seen as a core governmental responsibility by parties and people of all political positions, and therefore both publicly funded and delivered (Coulter 2019; Coulter and Fitzgerald 2016, 2019).

This paper provides the first overview of the Canadian cruelty investigations context and what lessons can be gleaned of both national and international significance. Canada is a bilingual (English and French) colonial country created on the traditional territories of many indigenous nations. Today the country is comprised of ten provinces and three territories. Canada has no national animal protection agency or animal welfare legislation. Instead, Canada's Criminal Code, the federal legislation that defines criminal offences, includes a small number of animal cruelty provisions. Canadian provinces have additional animal welfare laws. These laws commonly include exemptions for hunting, fishing, agricultural, and laboratory practices. While the data are inadequate, it is still clear that most illegal cruelty cases investigated involve companion animals. 
First, the public and private sector splits for enforcement and the corresponding mechanisms used for reporting suspected abuse are outlined. Then key statistical data about the types of cases identified and what is being done by investigators as a result are presented. To conclude, initial recommendations are posited, and a new concept, the animal harm spectrum, is explained to highlight how it can be mobilized to strengthen animal protection work and animal welfare policy across nations.

Notably, different terms are used to describe these policies and practices. Provincial legislation and organizational cultures refer to animal abuse, cruelty, neglect, and/or welfare, as well as to investigations, inspections, protection, and enforcement. At times these terms reflect specific contexts and particulars within those contexts (for example, neglect both falls under the umbrella of abuse but it also a specific kind of harm thereunder), although in some cases these terms are used almost interchangeably by those doing the work. This is terrain that is not linguistically tidy.

\section{Materials and Methods}

This paper extends from a larger research project focused on animal protection work and policy in Canada and around the world, particularly the United States and northern Europe, that began in 2015. It is mixed- and multi-method project and data are drawn from legislation, organizational policy and reports, interviews, focus groups, and field research, including with animal protection officers, animal care and shelter staff, police, forensic veterinarians, law enforcement leaders, policy makers, and lawyers across geographic regions. The goals are to assess the efficacy of policy and practice for (a) different groups of animals, (b) the front-line workforces, and (c) members of the public, including vulnerable people and human victims of violence. Because of the broad cross-section of organizations involved in animal protection, the research has involved studying charities (SPCAs and humane societies), municipal/local/county animal care and control services, general police forces, and dedicated animal protection units which may be housed within larger police services or positioned as stand-alone teams.

The findings presented here are drawn from this larger project and, in particular, from targeted online data collection undertaken in 2020 to map the Canadian enforcement terrain. A central outcome of this national case study was to create a comprehensive and freely available resource with an even larger pool of data, the web site AnimalProtection.ca. The data salient for this discussion are:

(i) which agencies are responsible where, and for which animals,

(ii) how reporting of suspected cruelty occurs,

(iii) what statistical data are available about the findings of investigations and types of cases.

These data are read in conjunction with pertinent social science scholarship in the generating of conclusions.

\section{Results}

\subsection{Canada's Public and Private Enforcement Patchwork}

As noted above, law enforcement is almost universally undertaken by publicly / taxfunded organizations and housed in the public sector. However, some charities have been tasked with this work specifically for investigations into suspected crimes against animals around the world, and within Canada. As nonprofits, these private organizations rely primarily on donations and fundraising for their operations.

Succinctly, in lieu of a unified national approach to animal enforcement in Canada, animal protection is provincially divided, and then, in many cases, further sub-divided based on geography and/or the types of animals (companion, farmed, wild). These divisions do not reflect a clear or predictable pattern. As a result, Canada's animal cruelty enforcement can be pictured as a patchwork-or even a patchwork of patchworks. It is also worth noting that the lives and deaths of animals who are defined as members of some or 
all of these categories simultaneously, such as rabbits (who are kept as companions, farmed for meat, and live in the wild), would be governed by different laws based on the context.

In all jurisdictions within Canada, public policing agencies can enforce provincial animal protection laws and the animal focused provisions of the Criminal Code. In other words, even when a province assigns responsibility for animal welfare investigations to an SPCA, this does not prohibit some occasional or area-specific public enforcement by police or public-nonprofit collaboration. However, in practice, it means the charity is the main body responsible, and often animal cruelty concerns are seen as the primary responsibility of that nonprofit by human-focused law enforcement. Therefore, when identified as a private responsibility in Table 1 , this means the large majority of the work is undertaken by an animal welfare charity.

Table 1. Public and Private Sector Enforcement Agencies by Province and Territory.

\begin{tabular}{|c|c|c|c|}
\hline Province/Territory (Population) & Public & Private & Mixed \\
\hline British Columbia (5.1 M) & & $\mathrm{x}$ & \\
\hline Alberta (7 M) & & & $\mathrm{x}$ \\
\hline Saskatchewan (1.2 M) & & & $\mathrm{x}$ \\
\hline Manitoba $(1.3 \mathrm{M})$ & & & $x^{*}$ \\
\hline Ontario (14.7 M) & $x^{* *}$ & & \\
\hline Quebec $(8.2 \mathrm{M})$ & & & $x$ \\
\hline Newfoundland \& Labrador (500 k) & $\mathrm{x}$ & & \\
\hline PEI $(160 \mathrm{k})$ & & & $x$ \\
\hline Nova Scotia (925 k) & & & $x$ \\
\hline New Brunswick (780 k) & & & $x$ \\
\hline Nunavut (36 k) & $\mathrm{x}$ & & \\
\hline Northwest Territories (42 k) & $x$ & & \\
\hline Yukon $(36 \mathrm{k})$ & $x$ & & \\
\hline
\end{tabular}

The public-nonprofit/private divisions may be based on geography with particular areas covered by public enforcement, while others are assigned to charities, but not in a predictable or consistent pattern. Put another way, it is not always urban areas with public enforcement, nor is it always rural areas.

At the same time, the public-private responsibility-sharing may be based on the types of animals and on their relationships to and with humans as companion animals, farmed animals, and wildlife-but this is not either uniform either. The result is a very uneven enforcement terrain.

The private sector, nonprofit organizations involved are humane societies and SPCAs. The public sector agencies involved are local police, provincial police, national police, provincial animal protection services, local/municipal bylaw officers (general not animal focused), and/or local/municipal animal bylaw officers/animal care and control services. Public agencies (conservation, natural resource, or municipal animal care and control officers) are more often responsible for suspected illegal harm to wild animals, for example, but not universally. The types of charges (e.g., Criminal Code and/or provincial offenses) that different investigators can lay vary.

British Columbia is the only Canadian province where the provincial SPCA is responsible for investigating suspected animal welfare and cruelty violations for all kinds of animals. Alberta is a mix of SPCA/humane society, municipal officers, and police undertaking investigations depending primarily on geography and on the severity of the issue. For example, in the city of Edmonton, the municipal animal care services will investigate suspected welfare violations, as will the Edmonton Police Service's newly created Animal Cruelty Investigations Unit - Canada's first - especially violent cases. In Calgary, people concerned about animal abuse are advised to call the humane society as the first responder, 
but the nonprofit's enforcement officers work regularly with local police, particularly a liaison who has prioritized animal cases.

In Saskatchewan, nonprofits-municipal humane societies and a provincial nonprofit that focuses exclusively on investigations-have responsibility for most suspected cruelty, but provincial conservation officers investigate suspected fishing, hunting, and wildlife violations. Québec's enforcement is geographically split between nonprofit and public, provincial agencies. The Maritime provinces of Nova Scotia, New Brunswick, and Prince Edward Island assign primary responsibility for companion animals in distress to SPCAs and humane societies, with provincial agricultural or conservation officers having jurisdiction for farmed and/or wild animals.

The province of Newfoundland and Labrador and the territories of Nunavut, the Northwest Territories, and Yukon have public enforcement, and it is the general police services that are responsible. Police officers may or may not any animal-specific training or significant familiarity with animal-focused criminal violations. Canada's most populated province, Ontario, is the only one which, as of 2020, has a dedicated and fully publicly funded and administered provincial animal protection team.

Manitoba is unique among provinces due to its publicly funded but hybrid publicprivate delivery/investigations model. Investigators are paid and appointed by the province but either work directly for the Chief Veterinary Office as government employees, the Winnipeg Humane Society as staff of the nonprofit, or, in most cases, are independent contractors (thus not legally defined as workers) (see Campbell 2019; Coulter and Campbell 2020 for further analysis of this unusual model).

When narrowed to companion animals (Table 2), the picture looks different.

Table 2. Responsibility for Investigations Involving Companion Animals.

\begin{tabular}{lccc}
\hline Province/Territory & Public & Private & Mixed \\
\hline British Columbia & & $\mathrm{x}$ & $\mathrm{x}$ \\
$\begin{array}{l}\text { Alberta } \\
\text { Saskatchewan }\end{array}$ & & $\mathrm{x}$ & $\mathrm{x}$ \\
$\begin{array}{l}\text { Manitoba } \\
\text { Ontario }\end{array}$ & $\mathrm{x} *$ & $\mathrm{x}$ \\
Quebec & $\mathrm{x}$ & & \\
Newfoundland \& Labrador & & $\mathrm{x}$ & \\
PEI & & $\mathrm{x}$ & \\
Nova Scotia & $\mathrm{x}$ & \\
New Brunswick & $\mathrm{x}$ & & \\
Nunavut & $\mathrm{x}$ & & \\
Northwest Territories & $\mathrm{x}$ & & \\
Yukon & & & \\
${ }^{*}$ publicly funded with mixed public-private delivery. ${ }^{* *}$ dedicated animal protection enforcement (rather than \\
general police). & &
\end{tabular}

Because the majority of calls reporting suspected harm are about companion animals, the agency doing the lioness' share of the investigative work in every jurisdiction is the one responsible for companion animals. For this reason, the majority of animal cruelty investigations in Canada are undertaken by nonprofits.

\subsection{Reporting}

Canadian jurisdictions rely almost entirely on a complaints-based reporting system. If members of the public see or otherwise suspect animal harm, it is incumbent on them to report their concerns. Veterinarians also have a legal duty to report suspected abuse. This is in contrast to automatic, or even unannounced inspections that can and do take place in other parts of the world, particularly northern Europe and Scandinavia, for properties other than residences. Certain Canadian provinces' laws have some provisions for announced inspections of businesses where animals are held for sale or display and, at the time of 
writing, the BC SPCA has announced plans to conduct more unannounced inspections of farms, a right afforded to it in the province's animal protection legislation. However, most suspected animal cruelty in private residences is only known to enforcement agencies if someone saw, heard, and/or smelled something concerning.

The task of reporting suspected violations is onerous and confusing in almost all provinces. Given the investigations patchwork, this is not surprising. In BC, where there is only one agency (the BCSPCA) responsible for the vast majority of investigations, a centralized phone reporting system is open during daytime hours. In Ontario and Manitoba, where provincial teams (albeit of different shapes) are dedicated to animal protection, there are also provincial hotlines.

In most provinces, however, a complex series of instructions are necessary depending on where the issue has taken place, what kind of animal it is, and what time of day or day of the week it is. This undoubtedly adds to the confusion and level of frustration people seeking to report suspected cruelty feel and can delay the amount of time that passes before animals in distress are identified and investigations initiated.

\subsection{Statistical Data: Investigators' Responses and Case Types}

Investigators seek to determine if there is an issue, and then the safest and most beneficial pathway(s) forward. Investigators may do one or more of the following:

- Determine that there is not sufficient evidence of animal harm and close the file

- Engage in discussion/verbal education and make recommendations for change

- Mandate behavior change (removal, addition, or change of something such as food, shelter, water, veterinary care, behavior, equipment), issue an order for compliance if available (such as in British Columbia and Ontario)

- Plan and undertake one or more follow-ups

- Provide resources directly (such as low- or no-cost veterinary care, food, enrichment items, etc.)

- Engage other services providers: animal-focused (e.g., pet food bank, animal charity) or human-focused (such as those providing housing support, health care, English/French language training, job search/training assistance, legal aid),

- Remove animal(s) (voluntary surrender or seizure)

- Obtain a warrant to search for additional evidence

- Bring of one or more other persons to assist (e.g., veterinarian, social worker, other law enforcement)

- Lay charges (provincial, criminal code)

Gathering comprehensive and robust statistical data about which of these steps investigators use in the field and how often, the kinds of animals involved, and the types of infractions (e.g., passive neglect, neglect, physical abuse, hoarding, etc.) is challenging. Statistics Canada, the publicly funded national agency responsible for information gathering and management, does not track animal cruelty. The enforcement patchwork further compounds the problem. There is no consistency across provinces or within provinces when there are multiple enforcement agencies, and some data-collection terms and categories used by the same organization have changed over time which prevents longitudinal analysis of patterns. This can be because of new responsibilities, or for other, unknown data management reasons. Often no data are made publicly available by enforcement agencies and/or were not supplied when requested.

Nevertheless, the data that are available shed some helpful light on investigations and responses. The following tables reflect the range of data that have been gathered, using the categories provided by the organizations in question. In other words, the categories across jurisdictions are not consistent but reflect the information that has been made available.

Tables 3 and 4 synthesize the data made publicly available in annual reports for two large provinces, British Columbia (population 5.1 million) and Ontario (population 14.7 million). 
Particularly noteworthy from the BC data (Table 3 ) is that the number of complaints nearly doubled over a ten-year period. This likely reflects a growing awareness about animal welfare among members of the public at large, although it may be indicative of an increase in the prevalence of problematic behavior. Also of note from these data is that the number of animals seized because of an investigation has remained quite steady. Because the number of complaints investigated increased substantially, the proportion of animals seized has decreased. In other words, this tool is being used less often by investigators. Categories that are blank do not mean these things did not occur but rather that details were not provided in the annual reports.

The Ontario SPCA was responsible for cruelty investigations for a century until it removed its enforcement role in 2019 and the provincial government created the public Provincial Animal Welfare Services.

The data from Ontario (Table 4) also demonstrate that both the total number and proportion of animals seized has decreased. The issuing of orders became more common and was the most frequently used tool identified. Not explicitly reflected in the table is how often educative action, the engaging of other service providers, or the direct provisioning of resources was used. However, based on the categories included, it is clear that routes outside the criminal justice system are used in a majority of cases.

Table 3. Statistical Data from British Columbia. Information compiled from BC SPCA Annual Reports.

\begin{tabular}{cccccc}
\hline Year & $\begin{array}{c}\text { Complaints } \\
\text { Investigated }\end{array}$ & $\begin{array}{c}\text { Warrants } \\
\text { Executed }\end{array}$ & $\begin{array}{c}\text { Charges of Animal } \\
\text { Cruelty and } \\
\text { Neglect }\end{array}$ & $\begin{array}{c}\text { Calls to } \\
\text { Provincial } \\
\text { Call Centre }\end{array}$ & $\begin{array}{c}\text { Animals Removed } \\
\text { Because of an } \\
\text { Investigation }\end{array}$ \\
\hline $\mathbf{2 0 0 8}$ & 4780 & - & - & - & 1297 \\
$\mathbf{2 0 0 9}$ & 5870 & 133 & 62 & - & 1332 \\
$\mathbf{2 0 1 0}$ & 7147 & 117 & 78 & - & 1249 \\
$\mathbf{2 0 1 1}$ & 7013 & 103 & 49 & - & 948 \\
$\mathbf{2 0 1 2}$ & 6042 & 85 & 43 & - & 869 \\
$\mathbf{2 0 1 3}$ & 7839 & 102 & 53 & - & 1340 \\
$\mathbf{2 0 1 4}$ & 8849 & 160 & 53 & 25,923 & 1110 \\
$\mathbf{2 0 1 5}$ & 10,205 & 148 & 26 & 26,671 & 1515 \\
$\mathbf{2 0 1 6}$ & 9788 & 140 & 89 & 28,494 & 1376 \\
$\mathbf{2 0 1 7}$ & 9334 & 121 & - & 29,583 & 1087 \\
$\mathbf{2 0 1 8}$ & 8009 & - & - & 31,482 & - \\
$\mathbf{2 0 1 9}$ & 8058 & - & & &
\end{tabular}

Table 4. Statistical Data from Ontario. Information compiled from OSPCA Annual Reports.

\begin{tabular}{|c|c|c|c|c|c|c|c|c|}
\hline Year & $\begin{array}{l}\text { Complaints } \\
\text { Investigated }\end{array}$ & $\begin{array}{l}\text { Orders } \\
\text { Issued }\end{array}$ & $\begin{array}{c}\text { Provincial } \\
\text { Charges } \\
\text { Laid }\end{array}$ & $\begin{array}{l}\text { Criminal } \\
\text { Charges } \\
\text { Laid }\end{array}$ & $\begin{array}{c}\text { Animals Removed } \\
\text { Because of an } \\
\text { Investigation }\end{array}$ & $\begin{array}{c}\text { Zoo } \\
\text { Inspections }\end{array}$ & $\begin{array}{c}\text { Zoos } \\
\text { Identified }\end{array}$ & $\begin{array}{l}\text { Zoos on } \\
\text { Registry }\end{array}$ \\
\hline 2010 & 13,096 & 2071 & 64 & - & 2221 & - & - & - \\
\hline 2011 & 12,819 & 1618 & 170 & 124 & 1991 & - & - & - \\
\hline 2012 & 16,483 & 2473 & 255 & 41 & 2016 & - & - & - \\
\hline 2013 & 17,680 & 2320 & 259 & 29 & 2469 & - & & - \\
\hline 2014 & 17,991 & 2756 & 348 & 26 & 1724 & - & - & - \\
\hline 2015 & 17,357 & 4241 & 334 & 21 & 1974 & 130 & 69 & 53 \\
\hline 2016 & 16,936 & 4289 & 444 & 22 & 1664 & 69 & 69 & 52 \\
\hline 2017 & 15,519 & 3988 & 573 & 21 & 1220 & 121 & 61 & 44 \\
\hline 2018 & 14,203 & 3630 & 499 & - & 1142 & 125 & 52 & 49 \\
\hline 2019 & \multicolumn{8}{|c|}{ Data are not available. } \\
\hline
\end{tabular}

As outlined, on 1 January 2020, a new publicly funded and delivered animal protection service was created. As a result, more and different data should become available.

Table 5 provides data from the province of Manitoba (population 1.4 M). Of the data currently available, this is the sole province with publicly funded cruelty investigations (see Coulter and Campbell 2020 for further details about the model). The most common issue identified in the province is consistently a standards of care violation. 
Table 6 outlines specific details from the province of Nova Scotia (population just under $1 \mathrm{M}$ ). There was a modest increase in complaints in the province of Nova Scotia, but the number remained quite consistent between 2015 and 2018. The chief provincial inspector explained that "general neglect" is the most common type of issue identified. This is akin to standards of care issues being the most common, consistent with Manitoba.

Table 5. Investigations Details from Manitoba. Data provided by the Ministry of Agriculture (Campbell 2019; Coulter and Campbell 2020).

\begin{tabular}{|c|c|c|c|}
\hline Year & Total Cases Filed & Largest Animal Welfare Concern & Most Inspected Species \\
\hline 2013 & 582 & $\mathrm{~N} / \mathrm{A}$ & Canine $(47 \%)$ \\
\hline 2014 & 696 & $\begin{array}{c}\text { N/A } \\
\text { [Act] } 2 \text { (1) (a) }\end{array}$ & Canine $(64.9 \%)$ \\
\hline 2015 & 798 & $\begin{array}{l}\text { Failure to ensure adequate source of food and water } \\
\text { for an animal }(51.75 \%) \\
\text { [Act } 2 \text { (1) (a) }\end{array}$ & Canine $(68.3 \%)$ \\
\hline 2016 & 952 & $\begin{array}{l}\text { Failure to ensure adequate source of food and water } \\
\text { for an animal }(43.8 \%) \\
\text { [Act }] 2(1)(\mathrm{a})\end{array}$ & Canine $(66.81 \%)$ \\
\hline 2017 & 1026 & $\begin{array}{l}\text { Failure to ensure adequate source of food and water } \\
\text { for an animal (52\%) } \\
\text { [Act] } 2 \text { (1) (a) }\end{array}$ & Canine $(64 \%)$ \\
\hline 2018 & 1054 & $\begin{array}{l}\text { Failure to ensure adequate source of food and water } \\
\text { for an animal }(52 \%)\end{array}$ & Canine $(66 \%)$ \\
\hline
\end{tabular}

Table 6. Investigations Details from Nova Scotia. Data provided by the Nova Scotia SPCA.

\begin{tabular}{|c|c|c|c|c|}
\hline Year & Complaints Reported & & Cases Investigated & $\begin{array}{c}\text { Highest Cruelty Calls by } \\
\text { Location }\end{array}$ \\
\hline 2014 & 1212 & & & \\
\hline 2015 & 1626 & & 1627 & Halifax Regional Municipality \\
\hline 2016 & 1648 & $\begin{array}{l}> \\
> \\
> \\
> \\
> \\
>\end{array}$ & $\begin{array}{l}180 \text { calls of abandonment } \\
187 \text { cases of direct abuse } \\
11 \text { cases of hoarding } \\
106 \text { inadequate shelters } \\
491 \text { cases of neglect } \\
330 \text { cases surrounding tethering } \\
80 \text { cases of unsanitary conditions } \\
116 \text { sick animals as well as other general complaints }\end{array}$ & Halifax Regional Municipality \\
\hline 2017 & 1615 & & & Halifax Regional Municipality \\
\hline 2018 & $1600+^{*}$ & $>$ & $\begin{array}{l}1900 \text { complaints investigated (total includes re-checks } \\
\text { from previous years) } \\
1934 \text { by-law investigations }\end{array}$ & Halifax Regional Municipality \\
\hline
\end{tabular}

The number of cases investigated in the city of Calgary (population 1.3 M) (Table 7) remained quite stable, other than the increase in medical neglect. The large number of animals who were seized, including the conspicuously high number in 2015, reflect the frequency of hoarding and the number of animals involved in those hoarding situations.

In a pattern consistent with other countries of the global north other than the United States (such as in Britain, Ireland, New Zealand, and Australia), a very small percentage of investigations result in provincial or criminal code charges. In 2017, data available reveal: $1 \%$ of investigations result in charges in BC (89/9334), $4 \%$ in Ontario $(59 / 15,519), 3 \%$ in Calgary (31/1075), and 3\% in most of rural Saskatchewan for 2016-17 (18/570) and 2\% for 2017-2018 (13/693). Officers in Ontario issued orders in $26 \%$ of investigations the same year $(3988 / 15,519)$. 
Table 7. Investigations Details from Calgary. Data provided by the Calgary Humane Society.

\begin{tabular}{|c|c|c|c|}
\hline Year & Total Cases Investigated & & Result/Breakdown of Investigations \\
\hline 2015 & 1419 & $>$ & $\begin{array}{l}2496 \text { seized animals } \\
43 \text { individuals charged }\end{array}$ \\
\hline 2016 & 1215 & $\begin{array}{l}> \\
>\end{array}$ & $\begin{array}{l}\text { Medical neglect accounted for } 20.6 \% \text { of the investigations } \\
659 \text { seized animals } \\
45 \text { individuals charged }\end{array}$ \\
\hline 2017 & 1075 & $>$ & $\begin{array}{l}435 \text { seized animals } \\
31 \text { individuals charged }\end{array}$ \\
\hline 2018 & 1059 & $>$ & $\begin{array}{l}557 \text { seized animals } \\
39 \text { individuals charged }\end{array}$ \\
\hline 2019 & 1093 & $\begin{array}{l}> \\
>\end{array}$ & $\begin{array}{l}496 \text { seized animals } \\
44 \text { Individuals charged } \\
\text { Medical Neglect up } 20 \%\end{array}$ \\
\hline
\end{tabular}

\section{Discussion}

Many people and organizations have shown leadership and confronted animal abuse and harm. Yet the landscape remains uneven and inequitable. It is difficult to navigate and chronically under-resourced. This is a challenge that plagues countries around the world without national animal protection infrastructure. As noted, the organizations responsible for investigations are a patchwork of patchworks with no consistent or predictable pattern around the country. The fundamental question of whether investigations should be a public or private responsibility is salient, but not the focus in this paper. A potential role for the federal government or federal agencies is also an important consideration, given the more robust financial resources available and potential for targeted provincial transfer payments, pan-Canadian coordination and national standards, among other factors. This is something that warrants greater consideration. These core issues of public versus private sector enforcement and scale are not unique to Canada and raise important questions about how animal protection is organized and funded globally.

Two modest recommendations are offered to help strengthen the organization and operations of animal protection in Canada in the short term, as a start.

1. Reporting mechanisms should be streamlined. The easier it is for members of the public to report suspected cruelty, the more likely they are to do it. Regardless of which agencies are responsible for what kind of investigations or animals, the public should not have to sort out who to call. Well-trained dispatchers should be employed who gather as much as information as possible, and then they should communicate with the most appropriate individual(s) and agency.

Qualitative research findings from the project suggest that phone calls are the best method so that dispatchers can ask specific and follow-up questions and try to rule out incorrect or nonexistent addresses (a recurring problem). Given our heavily device-reliant online culture, a clear online tool could be useful, but a hotline is preferable for the reasons outlined. A single, well-publicized phone number/hotline would be useful for every province. This should be a public responsibility and funded by provincial governments, regardless of what organizations are assigned front-line investigations. It would be a modest investment in animals' wellbeing and public safety.

More ambitiously, there could be a role for the federal government: one, single animal protection line/tool for the entire country, staffed 24-7 by knowledgeable, highly trained public servants who can gather the needed information and then dispatch accordingly 
based on the province and locality in question. These are not uncommon internationally for reporting suspected child and elder abuse.

2. Data gathering should be coordinated to ensure consistency and better tracking. The current, highly uneven cross-section of animal cruelty and welfare statistics is not serving animals, officers, organizations, policy makers, or members of the public well. To begin to remedy this, two paths would be useful.

(A) Existing investigations agencies should collectively determine what to record-and then document it consistently. This does not prevent provincial or local bodies from collecting additional data; instead, it means that a specific set of information would be gathered by everyone to allow for careful, accurate information keeping. There is a clear opportunity and need for greater collaboration and the collecting of consistent and useful data to inform public and organizational policy making in the interest of better protecting animals, more carefully understanding types of infractions, and better equipping investigators with the appropriate knowledge and tools.

(B) Statistics Canada should be gathering animal cruelty statistics. This is long overdue and a public data gathering failure that should be corrected.

\section{Conclusions}

Building from the available statistics, from six years of primary research, and from the sociological and green criminological literatures on animal abuse (e.g., Fitzgerald et al. 2013; Nurse 2016, 2021; Reese et al. 2020; Taylor and Fitzgerald 2018), this paper concludes by presenting the concept of the animal harm spectrum. Cases involving animals and suspected legal violations exist on a continuum (see Figure 1.)

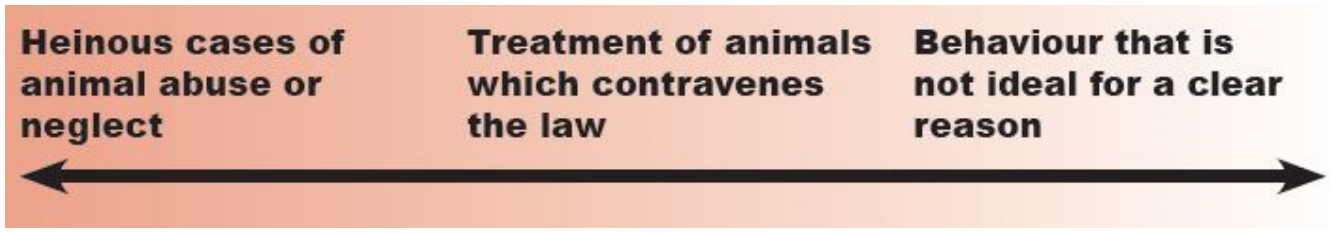

Figure 1. The Animal Harm Spectrum.

The most significant reason the spectrum (or continuum) is valuable is because it emphasizes the importance of having a cross-section of tools and responsive strategies available. The term "investigations" is used for a clear reason: front-line workers need to actively assess the animal(s), the situation, the environment, and the particulars in order to determine if there is evidence that the law is being violated, and then what the best course of action(s) should be, for the wellbeing of the animal(s), the people (animal caretakers, family members, neighbors), and the officers' own safety. Effective animal protection investigations recognize context-specific factors including the different reasons animals are or may be at risk, shared and distinct human-animal vulnerabilities, and the likely or potential results of different responses.

Heinous cases of animal abuse are the most serious and dangerous. They normally require extensive evidence gathering and can include removal of animal(s). They more often result in charges.

These cases are the most violent. They can include acts taken such as stabbing, burning, crushing, cutting, punching, kicking, dragging, and/or throwing animals, animal fighting, serious hoarding, and bestiality. They can also include a lack of action causing serious or fatal harm such as the continuous deprivation of water, food, shelter, or medical care. People may be being abused alongside animals, or the animal abuse may serve as an indicator of future violence. This is known as the human-animal violence link and it must be taken seriously (Alleyne and Parfitt 2019; Ascione et al. 2007; Flynn 2008). There are dangerous offenders who sadistically harm animals, who abuse animals before or alongside other people, and/or who threaten, maim, and murder animals as strategies of control 
and domination, particularly in cases of interpersonal violence against women. These patterns are consistent internationally, and the data from Canada are very concerning: $89 \%$ of women in domestic violence shelters report that the abuser threatened to and/or harmed their animals at (Fitzgerald et al. 2020). Thankfully there are fewer of these cases, but they require careful, professional, and serious attention from experts in law enforcement and in the larger criminal justice system.

Treatment of animals which contravenes the law normally has already and/or could cause harm but is not as serious and/or violent. These cases could include not providing sufficient water, food, shelter, or medical care, sharply correcting a dog, hitting an animal. These cases can escalate and warrant more serious responses like charges, or the problem can be resolved without further harm being done to the animal(s). Front-line workers must determine whether legally binding corrective action is the best course of action. Alternatively, front-line workers may decide that the situation warrants corrective action and education.

In these cases, officers use their knowledge, experience, and skills to make decisions about which path(s) is/are the best to pursue based on many factors including the person's attitude and likelihood of compliance, the person's level of knowledge, the person's financial resources, their degree of agitation and the resulting potential safety concerns, whether it is a first time or repeated issue, among other dimensions. As outlined, it is also possible to not use legally binding tools initially but to enlist them if behavior does not change and the situation is not corrected.

Behavior that is not ideal for a clear reason reflects the cases normally deemed to warrant empathy and problem solving. Examples could include someone made an isolated mistake which did not do harm; someone who is struggling with a disability, injury, or disease; someone who lacks financial resources, loves their animal, and needs help with caring for their animal (food, veterinary care) or for themselves (social services, housing, health care).

Again, front-line workers assess the situation in context and may decide education and behavior change may be necessary, and/or that assistance, supports, or resources are essential. They may be able to provide direct assistance if their employer or a partner organization provides free food or low- or no-cost veterinary care, or they may connect people with a suitable service or program or engage the pertinent organization(s) in the hopes that the help needed can be provided to help the person and the animal.

Behavior may change over time and move to a different position on the spectrum, thus warrant a different response. Crucially, the animal harm spectrum reflects the realities of varied people, animals, situations, and environments, and that different responses are important in the interest of creating humane investigations that take people's and animals' wellbeing seriously. It recognizes that all individual cases investigated may not involve cruelty as legally defined, but that harm may still be occurring or imminent. The concept also challenges us to recognize a broader constellation of organizations and individuals involved in addition to front-line investigators when thinking about animal protection. Organizations, whenever possible, should be ensuring they have a range of tools and strategies available to respond, or that they can engage partners as necessary.

In other words, while the process may begin as/with law enforcement, a criminal justice response may or may not be the most useful or appropriate result. For mental health issues that may lead to or are already manifesting in serious harm to animals and/or people (including abuse, neglect, hoarding), criminal justice responses may be necessary to protect and/or remove animals and/or people and mandate treatment, or as one part of a multi-sector response including social services. But when the risk to animals is minimal and especially when people are wanting to provide good care for their animals but struggling, problem solving solutions are often not only more empathetic but also more effective. Criminal justice routes should be engaged when necessary, for the safety of animals and people, but not the only option. 
The importance of the human-animal bond-that is, the physical, psychological, and social benefits of companionship with animals for people-has been recognized in different forms since the 1970s (Hines 2003), especially for marginalized individuals and social groups. Moreover, an awareness of shared vulnerabilities and the need to consider whether people are deliberately harming animals have long been an essential part of animal protection efforts. Various nonprofits, including humane societies, SPCAs, and specifically created organizations, have programs of different kinds that seek to provide resources to support people who are trying to care for their animals. Providing low or no cost food, litter, and veterinary treatments (ranging from spay/neuter to other veterinary services) are the most common approaches. Front-line investigators may engage these other supports or refer people to them, the services may be consistently available for people to access on their own, and, in some cases, the program may be physically rolled into a community proactively (such as with mobile veterinary units).

More research into how to both prevent and respond to interpersonal violence and different kinds of crimes against animals is sorely needed in order to thoughtfully inform front-line work and help create a more ethical and effective criminal justice system - and society. In addition to critique, we need alternatives and efficacious pathways forward. Rigorous data are helpful for informing effective policy and practice.

Statistics are by no means the only way to measure or assess the effectiveness of animal protection work or cruelty investigations, but they are needed. Similarly, a low number of charges does not mean animal abuse is not serious, or that front-line efforts are failing. Solving and preventing problems by connecting vulnerable people with the needed supports and resources, educating people so they improve their behavior in ways that meaningfully augment animals' quality of life, and so on, are not normally quantified but are significant successes, nevertheless. Undoubtedly, there is a significant need for greater coordination and consistency in quantitative data collection, as well as more qualitative research internationally to better respond to the animal harm spectrum and, ideally, to both prevent abuse and promote the wellbeing of animals—and people.

Funding: This research has received funding from the Social Sciences and Humanities Research Council of Canada, grant 435-2019-0175.

Institutional Review Board Statement: All research included in this article was approved by the Brock University Research Ethics Board.

Informed Consent Statement: Informed consent was obtained from all subjects involved in the study.

Data Availability Statement: Provincial and territorial details are freely available at AnimalProtection. ca (accessed on 9 September 2021).

Acknowledgments: Thanks to Brittany Campbell and Bridget Nicholls for the research assistance.

Conflicts of Interest: The author declares no conflict of interest. The funders had no role in the design of the study; in the collection, analyses, or interpretation of data; in the writing of the manuscript, or in the decision to publish the results.

\section{References}

Alleyne, Emma, and Charlotte Parfitt. 2019. Adult-perpetrated animal abuse: A systematic literature review. Trauma, Violence, E Abuse 20: 344-57.

Ascione, Frank R., Claudia V. Weber, Teresa M. Thompson, John Heath, Mika Maruyama, and Kentaro Hayashi. 2007. Battered pets and domestic violence: Animal abuse reported by women experiencing intimate violence and by nonabused women. Violence Against Women 13: 354-73. [CrossRef] [PubMed]

Campbell, Brittany. 2019. Protecting Animals and People: The Role of the Public Sector in Improving Animal Cruelty Investigation Work. MA thesis. Available online: https:/ / dr.library.brocku.ca/handle/10464/14545 (accessed on 9 September 2021).

Coulter, Kendra. 2019. Towards a Safer and More Humane Ontario (Report). Available online: humanejobs.org/reports (accessed on 9 September 2021).

Coulter, Kendra, and Brittany Campbell. 2020. Public investment in animal protection work: Data from Manitoba, Canada. Animals 10: 516. [CrossRef] 
Coulter, Kendra, and Amy Fitzgerald. 2016. Difference Makers: Understanding and Improving the OSPCA's Animal Cruelty Investigations Work (Report). Available online: humanejobs.org/reports. (accessed on 9 September 2021).

Coulter, Kendra, and Amy Fitzgerald. 2019. The compounding feminization of animal cruelty investigation work and its multispecies implications. Gender, Work and Organization 2: 288-302. [CrossRef]

Fitzgerald, Amy J., Rochelle Stevenson, and Anthony R. Verbora. 2013. Sociological theories of animal abuse. In Animal Cruelty: A Multidisciplinary Approach to Understanding. Edited by Mary P. Brewster and Cassandra L. Reyes. Durham: Carolina University Press, pp. 285-306.

Fitzgerald, Amy J., Betty Jo Barrett, Allison Gray, and Chi Ho Cheung. 2020. The connection between animal abuse, emotional abuse, and financial abuse in intimate relationships: Evidence from a nationally representative sample of the general public. Journal of Interpersonal Violence 15-16. [CrossRef]

Flynn, Clifton P. 2008. A sociological analysis of animal abuse. In International Handbook of Animal Abuse and Cruelty: Theory, Research, and Application. West Lafayette: Purdue University Press, pp. 155-74.

Hines, Linda M. 2003. Historical perspectives on the human-animal bond. American Behavioral Scientist 47: 7-15. [CrossRef]

Hughes, Gordon, and Claire Lawson. 2011. RSPCA and the criminology of social control. Crime, Law and Social Change 55: 375-89. [CrossRef]

Morton, Rochelle, Michelle L. Hebart, Rachel A. Ankeny, and Alexandra L. Whittaker. 2021. Assessing the Uniformity in Australian Animal Protection Law: A Statutory Comparison. Animals 11: 35. [CrossRef] [PubMed]

National Link Coalition. 2021. How Do I Report Suspected Abuse? Available online: https://nationallinkcoalition.org/how-do-ireport-suspected-abuse (accessed on 9 September 2021).

Nurse, Angus. 2016. Animal Harm: Perspectives on Why People Harm and Kill Animals. London: Routledge.

Nurse, Angus. 2021. Green criminological perspectives on dog-fighting as organised masculinities-based animal harm. Trends in Organized Crime, 1-20. [CrossRef]

Reese, Laura A., Joshua J. Vertalka, and Cassie Richard. 2020. Animal cruelty and neighborhood conditions. Animals 10: 2095. [CrossRef] [PubMed]

Rodriguez Ferrere, Marcelo, Mike King, and Levi Mros Larsen. 2019. Animal Welfare in New Zealand: Oversight, Compliance, and Enforcement (Report). Available online: https:/ / ourarchive.otago.ac.nz/handle/10523/9276 (accessed on 9 September 2021).

Taylor, Nik, and Amy Fitzgerald. 2018. Understanding animal (ab)use: Green criminological contributions, missed opportunities and a way forward. Theoretical Criminology 22: 402-25. [CrossRef] 